\title{
Prosthodontic Management of Completely Edentulous Patient with Unilateral Facial Paralysis
}

\author{
${ }^{1}$ Raveena Makker, ${ }^{2}$ Vivek Choukse
}

\begin{abstract}
Rehabilitation of compromised patients has always been a challenge to the medical field. Prosthodontic management of completely edentulous patient with unilateral facial paralysis is a difficult task to accomplish. This requires alteration of conventional procedures.

This article presents a case report of a completely edentulous patient with facial paralysis of left side since 3 years. To enhance function and esthetics, a liquid-supported denture was planned for maxillary arch and neutral zone technique for mandibular arch.
\end{abstract}

Keywords: Facial paralysis, Liquid-supported denture, Neutral zone.

How to cite this article: Makker R, Choukse V. Prosthodontic Management of Completely Edentulous Patient with Unilateral Facial Paralysis. J Oral Health Comm Dent 2018;12(1):31-36.

Source of support: Nil

Conflict of interest: None

\section{INTRODUCTION}

Facial paralysis is loss of facial movement because of facial nerve damage. The facial muscles become drooped or weak. It usually happens on just one side of the face and is typically caused by infection or inflammation of the facial nerve, head trauma, head or neck tumor or stroke. ${ }^{1}$

Facial paralysis can come on suddenly or can happen gradually over a period of months. Depending on the cause, the paralysis might last for a short or extended period of time.

Facial paralysis has a major impact on a person's quality of life. It can cause facial pain, headache or dizziness, earaches, difficulty in talking, eating and drinking,

\footnotetext{
${ }^{1}$ Senior Lecturer, ${ }^{2}$ Professor

${ }^{1}$ Department of Prosthodontics and Crown and Bridge, Index Institute of Dental Sciences, Indore, Madhya Pradesh, India

${ }^{2}$ Department of Prosthodontics and Crown and Bridge, Modern Dental College \& Research Centre, Indore, Madhya Pradesh India

Corresponding Author: Raveena Makker, Senior Lecturer Department of Prosthodontics and Crown and Bridge, Index Institute of Dental Sciences, Indore, Madhya Pradesh, India Phone: +919993062678, e-mail: raveena.makker@yahoo.com
}

inability to express emotion, drooling, muscle twitching, tearing of eye, and dryness of eye and mouth. The problems encountered during prosthodontic rehabilitation include uncontrolled flow of saliva, dryness of mouth, and poor muscle coordination. All features may interfere with steps in impression making, jaw relation, and denture retention and stability, which may necessitate modification of conventional complete denture procedures.

\section{CASE REPORT}

A 74-year-old completely edentulous male patient reported to the Department of Prosthodontics, Modern Dental College \& Research Centre, Indore, with a chief complaint of inability to chew food and unesthetic appearance of face. History revealed that the patient had suffered from facial paralysis of the left side of face 3 years earlier (Fig. 1).

On extraoral examination, asymmetry of face was noticed with loss of muscle tone on the paralyzed side. The face was drawn to the right side during phonation. There was drooping of the corner of the mouth on the affected side, and there were uncoordinated movements of the lower jaw.

According to House and Brackmann ${ }^{2}$ classification, his condition was classified as grade III, i.e., moderate dysfunction-obvious but not disfiguring difference between two sides; noticeable but not severe synkinesis, contracture and/or hemifacial spasm with slight to moderate forehead motion, and complete closure of eye with effort.

Intraoral examination revealed resorbed maxillary and mandibular completely edentulous ridges in class II relationship (Fig. 2).

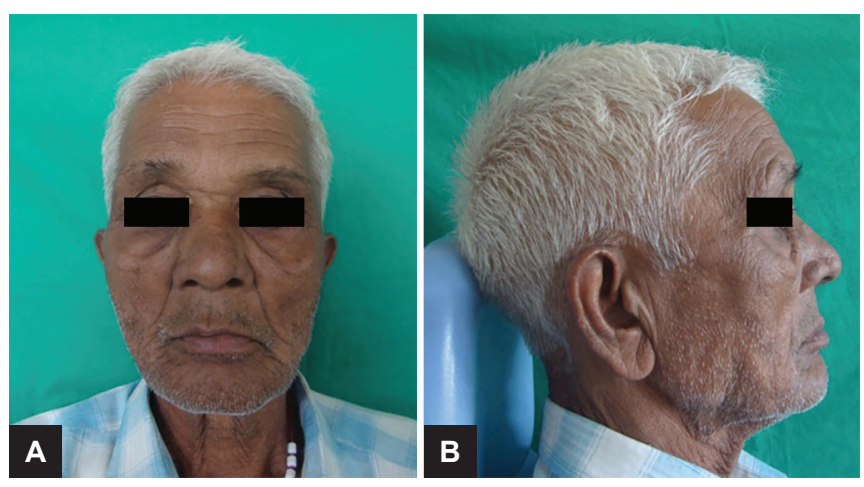

Figs 1A and B: Preoperative view 

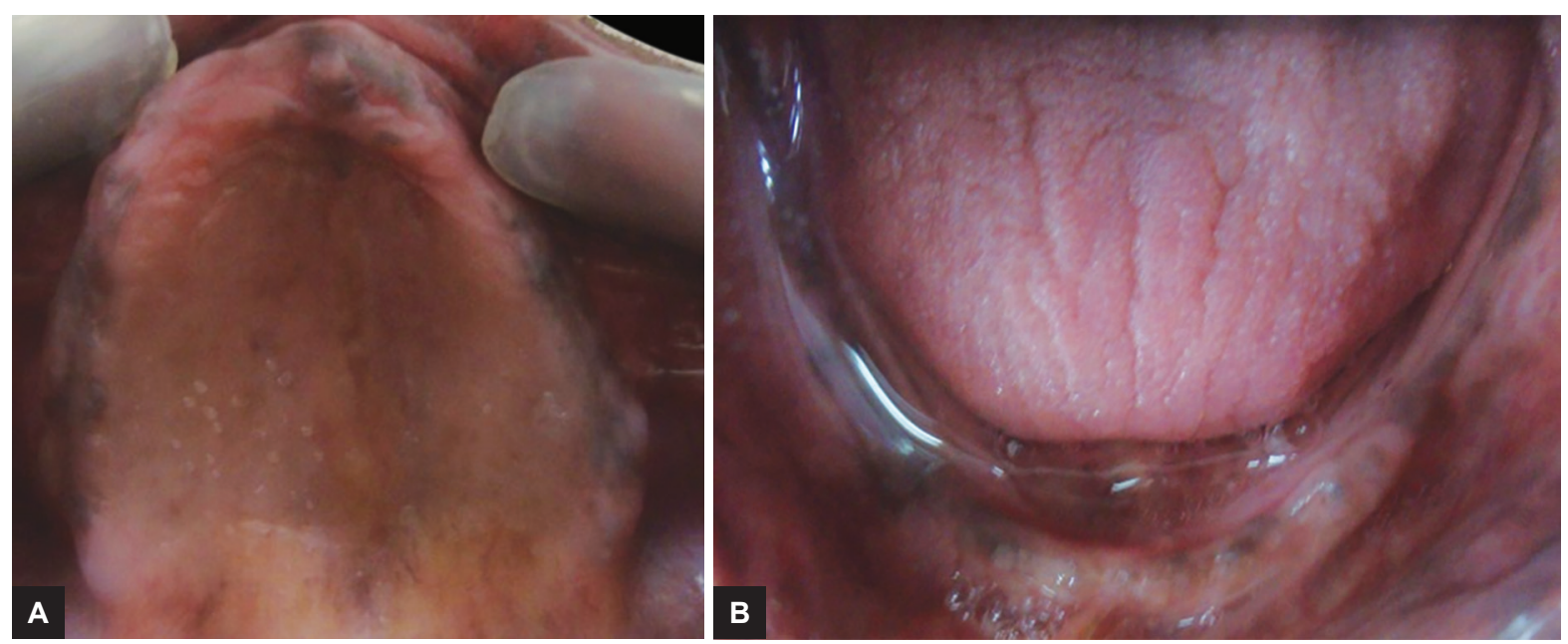

Figs 2A and B: Resorbed maxillary and mandibular ridges

Neuromuscular function and coordination are foundation for successful and stable dentures. The success of any prosthesis depends on the proper position of the artificial teeth within the neutral zone. Failure to recognize the importance of tooth position, flange form, and contour often results in dentures which are unstable and unsatisfactory. In unilateral facial paralysis patient, it is essential to record neutral zone because of imbalanced forces generated by unaffected and affected side causing instability in dentures. ${ }^{3,4}$

Patients with diabetes, xerostomia, and atrophied ridges present problems in stability, retention, and soreness that can result in hyperemia of the palatal mucosa. ${ }^{5}$ Liquid-supported denture can be a permanent solution in these patients. ${ }^{6}$ Liquid-supported dentures will have optimal stress distribution during masticatory function. Rehabilitation of these patients is a challenging task to fulfill. Hence, a liquid-supported denture was planned for maxillary arch and neutral zone concept for fabrication of contour of the polished surfaces of mandibular denture to enhance denture stability.

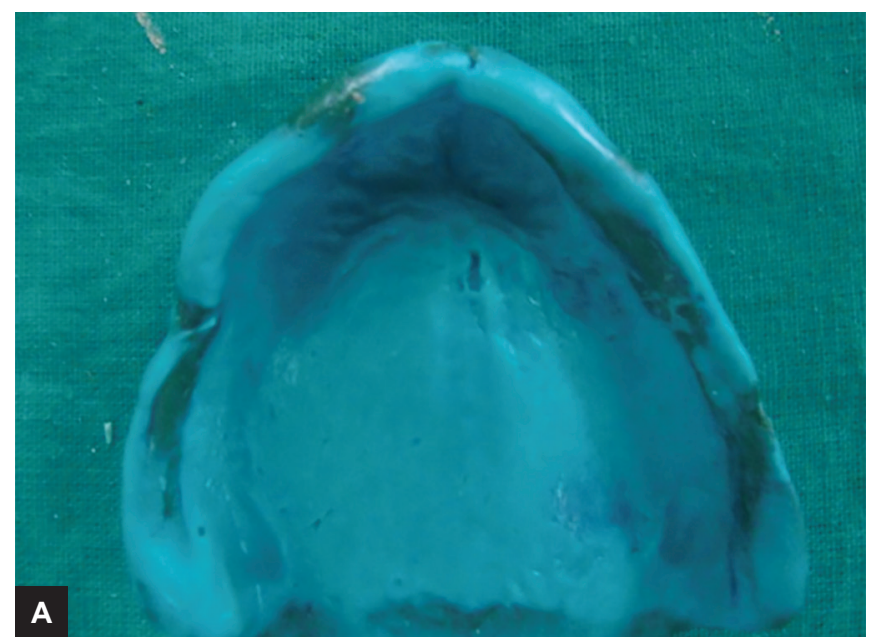

A preliminary impression of the maxillary and mandibular arches was made with impression compound (Y-Dents Impression Composition), and impressions were poured with dental plaster (Neelkanth), and the primary casts were retrieved. It was followed by border molding with low-fusing compound (DPI Pinnacle) and final impression with light body impression material (Aquasil Ultrapolyvinyl siloxane) (Fig. 3).

The obtained impressions were poured with dental stone (Denstone). The record bases (Trevalon) were fabricated, assessed, and modified for stability, extension, and comfort. Before making the neutral zone impression, the patient was made comfortable in an upright position with the head supported. The impression material (Green Impression Compound; DPI Pinnacle) was softened in a $65^{\circ} \mathrm{C}$ water bath. The softened compound was kneaded and a roll was formed according to the crest and was attached to the base. The attached roll of compound was reheated in the water bath and was carried into the patient's mouth. With the record base firmly seated, the patient was asked to perform a series of actions like

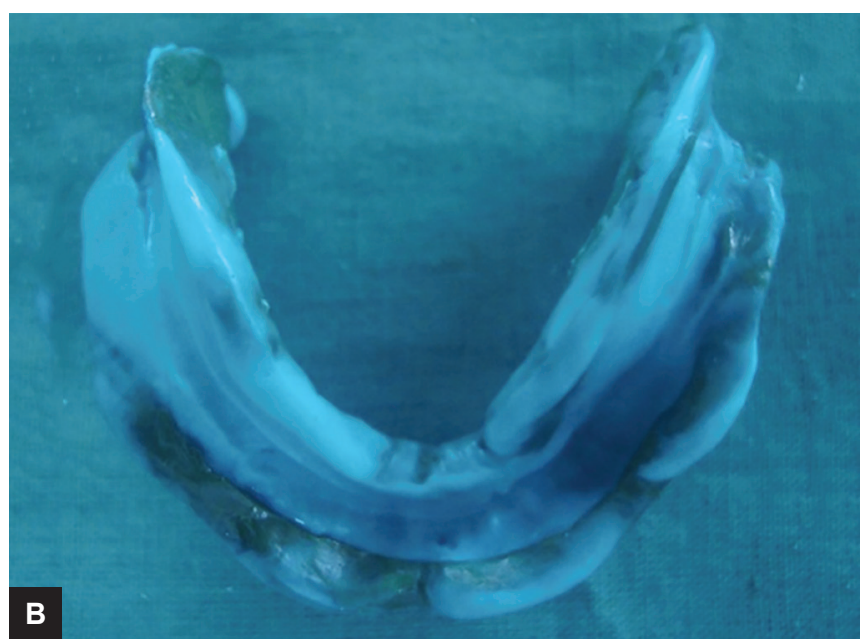

Figs $3 \mathrm{~A}$ and $\mathrm{B}$ : Final impression 


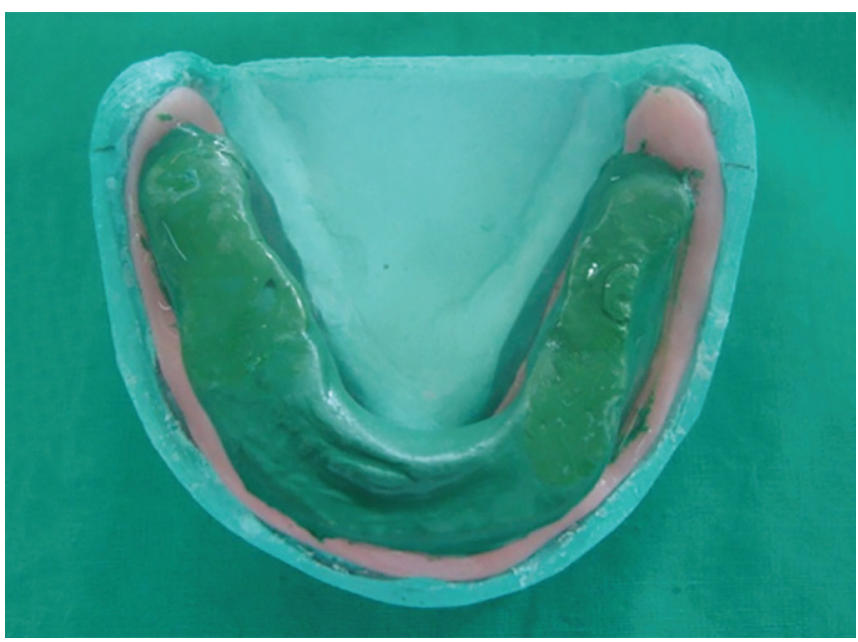

Fig. 4: Neutral zone recorded with low fusing impression compound

swallowing, speaking, sucking, pursing lips, pronouncing vowels, sipping water, and slightly protruding the tongue several times which simulated physiological functioning. During function of the lips, cheeks, and the tongue, the forces exerted on the soft compound mold it into the shape of the neutral zone (Fig. 4).
After a few minutes when the compound has cooled, the record base with the compound rim is removed and placed in cool water bath. Maxillary rim was oriented in the patient's mouth, the height of the lower compound rim was adjusted with a sharp knife, and tentative jaw registration was carried out and face bow transfer done on a semi-adjustable articulator (Hanau Wide Vue) (Figs 5 and 6).

The neutral zone impression so obtained was placed on the master model, and locating grooves (three facially: One anterior and two posterior, while two grooves lingually: One anterior and one posterior) were cut on the master cast and covered with a silicone putty index (Aquasil Soft Putty/Regular Set) around the impression on both the labial and lingual sides (Fig. 7).

The compound mandibular occlusal rim was then removed from the base plate and was replaced by the index preserving the space of neutral zone. Teeth arrangement was done exactly following the index (Fig. 8). The position of the teeth was checked by placing the index together around the wax try-in. The wax trial dentures were tried intraorally to check the appearance and occlusion.
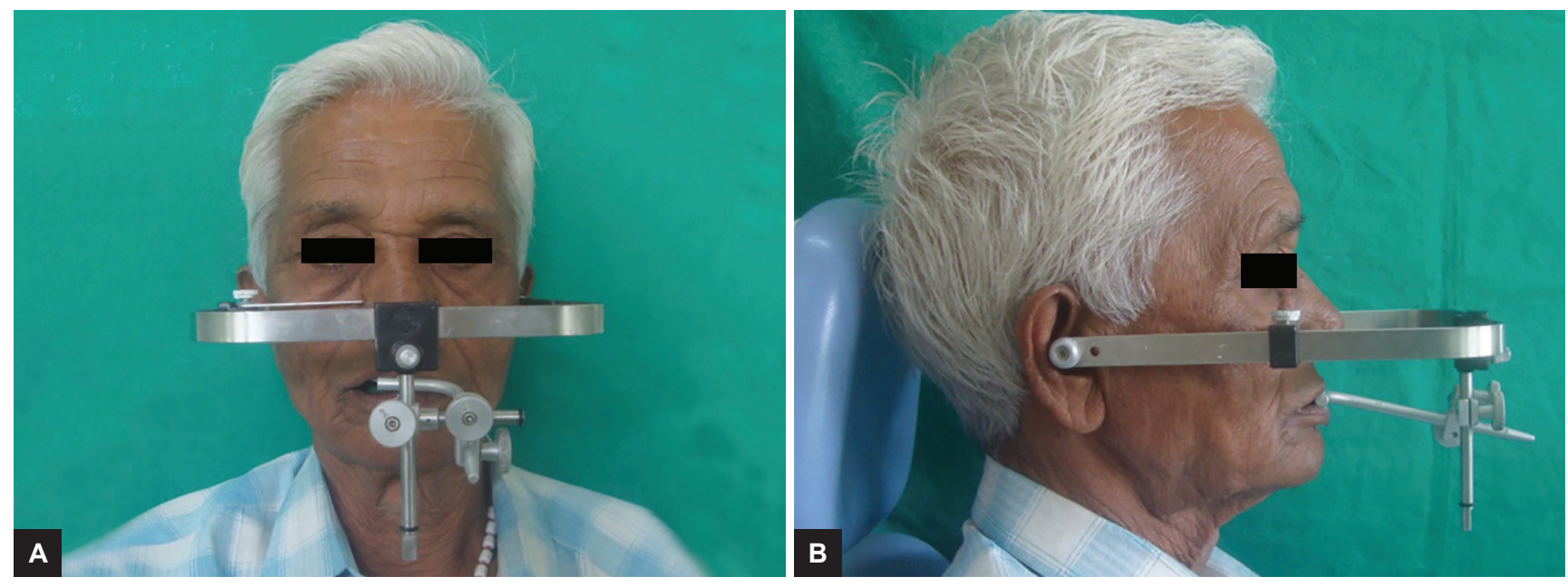

Figs 5A and B: Facebow transfer

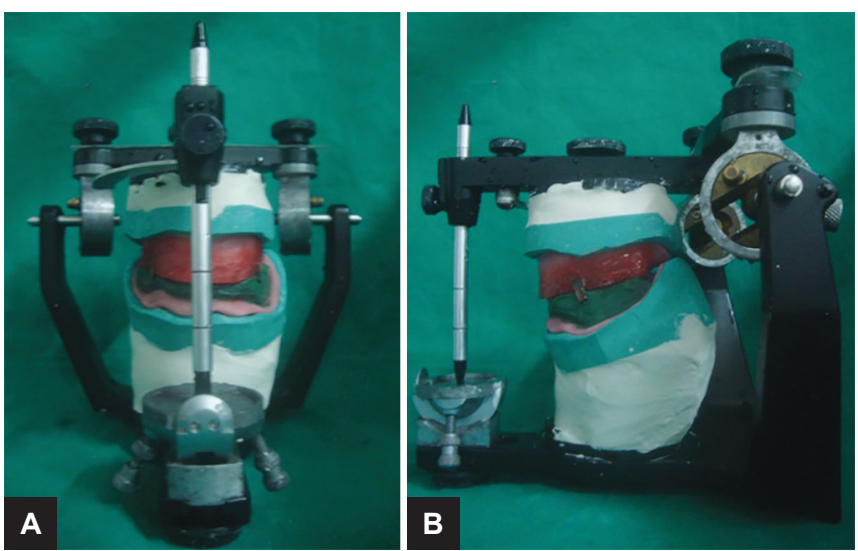

Figs $6 A$ and $B$ : Articulated casts on semi-adjustable articulator (Hanau Wide Vue)

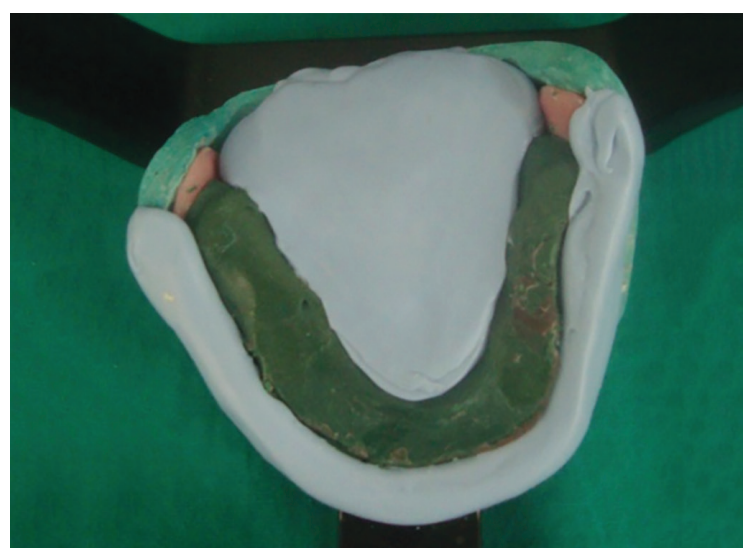

Fig. 7: Silicone putty index 

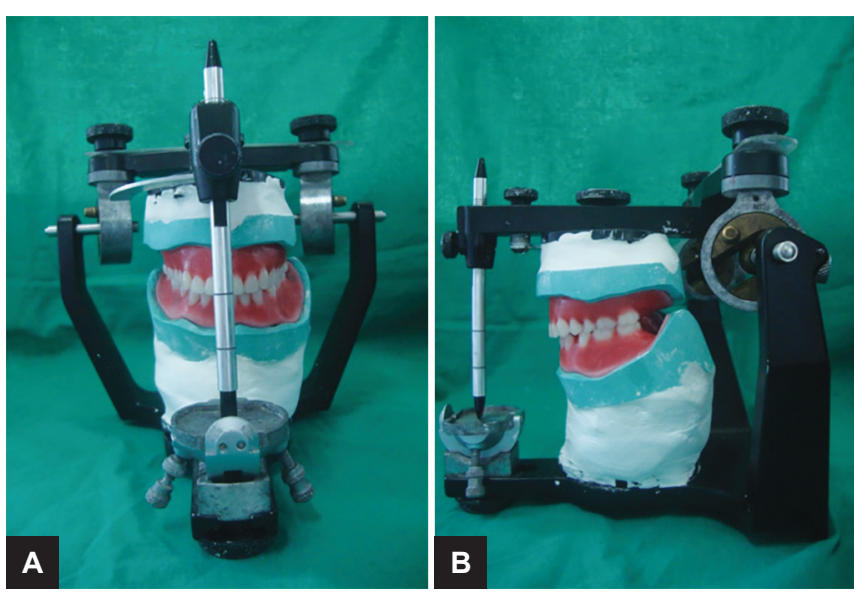

Figs $8 \mathrm{~A}$ and $\mathrm{B}$ : Teeth arrangement in neutral zone

\section{LABORATORY PROCEDURE}

\section{Stage I}

At the time of packing, a $1 \mathrm{~mm}$ thick, soft, flexible polyethylene sheet (Easy-Vac Gasket GB 040) was incorporated in the maxillary denture which was $2 \mathrm{~mm}$ short of the borders. This sheet was adapted over the master cast with the help of a vacuum heat-pressed machine (Fig. 9).

Then, the sheet along with the heat-cure denture base resin (Trevalon) was packed to facilitate proper sealing. The denture was then finished, polished, and inserted into the patient's mouth to check for retention, stability, support, and border extension (Fig. 10).

The patient was asked to use the denture for 2 weeks till he got adjusted to the new dentures.

\section{Stage II}

The maxillary denture was now ready to be converted into a liquid-supported denture. A putty (Aquasil, polyvinyl siloxane) impression of the tissue surface of

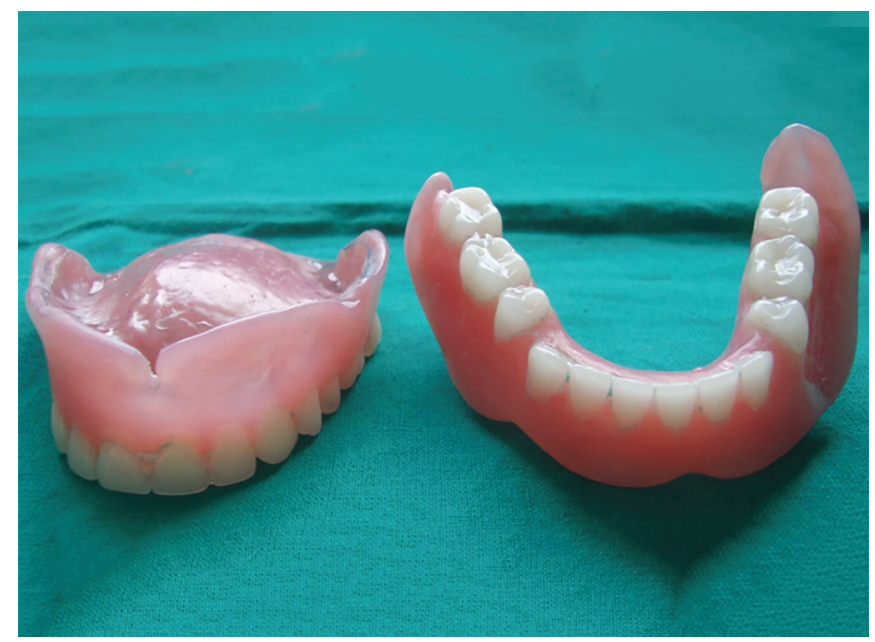

Fig. 10: Finished complete denture

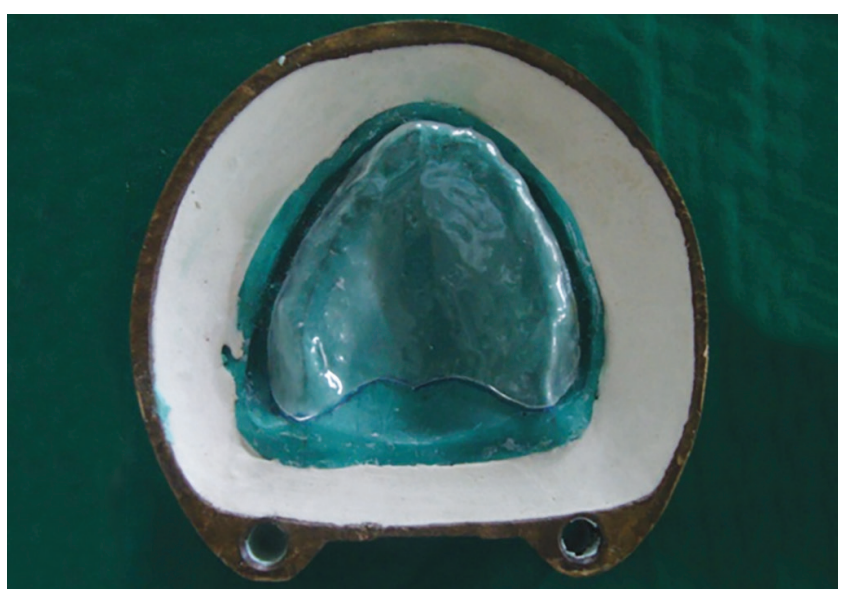

Fig. 9: Adapted vacuum form sheet of $1 \mathrm{~mm}$ incorporated at the time of packing

the maxillary denture was obtained to get the junction of the temporary sheet and the denture base resin. The impression was poured with dental stone, and the positive replica of the denture was obtained with the junction marked over it.

A new polyethylene sheet of $0.5 \mathrm{~mm}$ thickness (EasyVac Gasket GB 020) was adapted on this stone replica, again vacuum-pressed and cut into the desired shape as on the stone replica to form the ultimate denture base. This sheet was a permanent one of $0.5 \mathrm{~mm}$ thickness as compared with the temporary one which was $1 \mathrm{~mm}$ thick. This difference in space was occupied by liquid in the final prosthesis.

The temporary $1 \mathrm{~mm}$ thick sheet/spacer embedded in the denture was replaced with the new $0.55 \mathrm{~mm}$ thick permanent sheet in the final denture (Fig. 11). Two holes were made in the denture buccally in the molar region (Fig. 12).

The permanent polyethylene sheet was then incorporated in the denture base with cyanoacrylate adhesive.

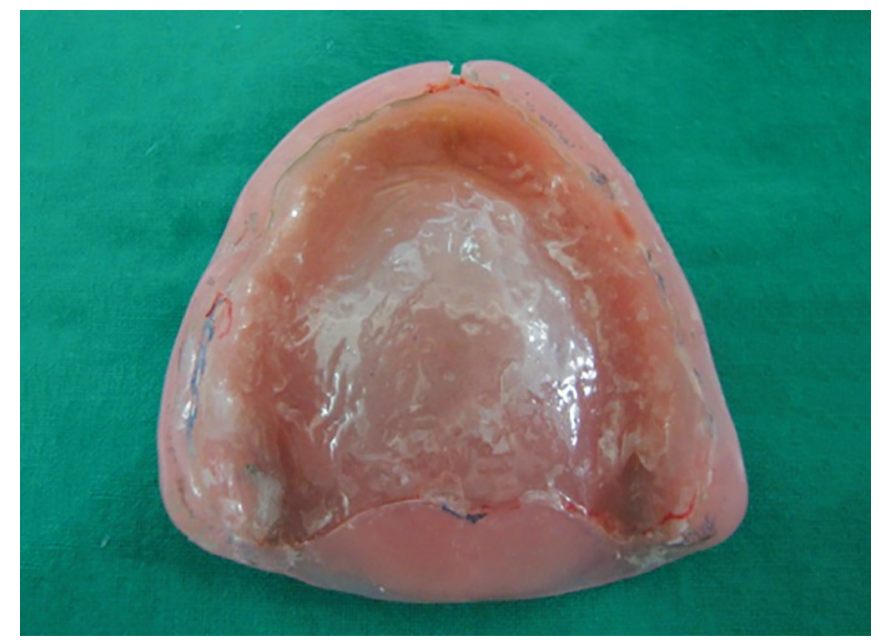

Fig. 11: Replacement of $1 \mathrm{~mm}$ sheet with $0.5 \mathrm{~mm}$ sheet vacuum heat-pressed polyethylene sheet 


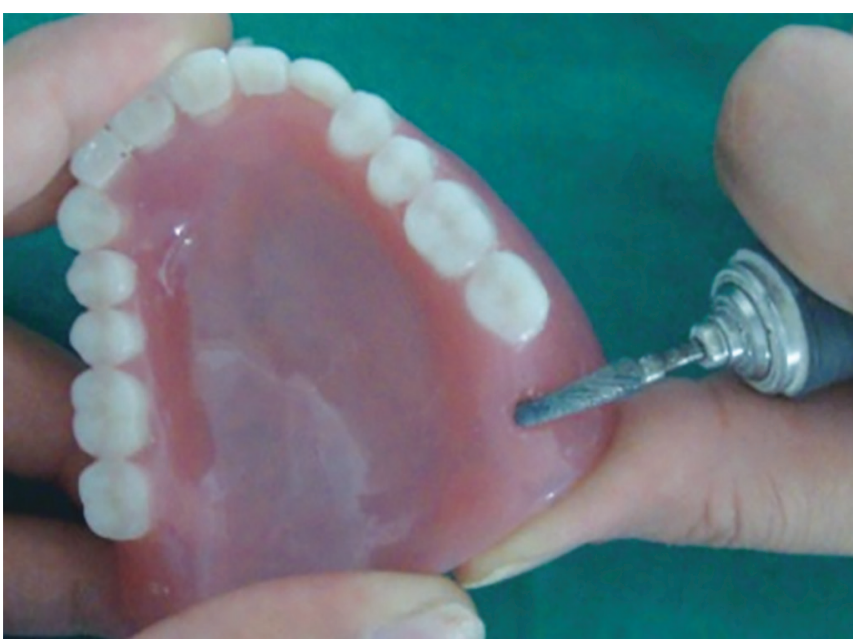

Fig. 12: Holes made in the denture for injecting liquid

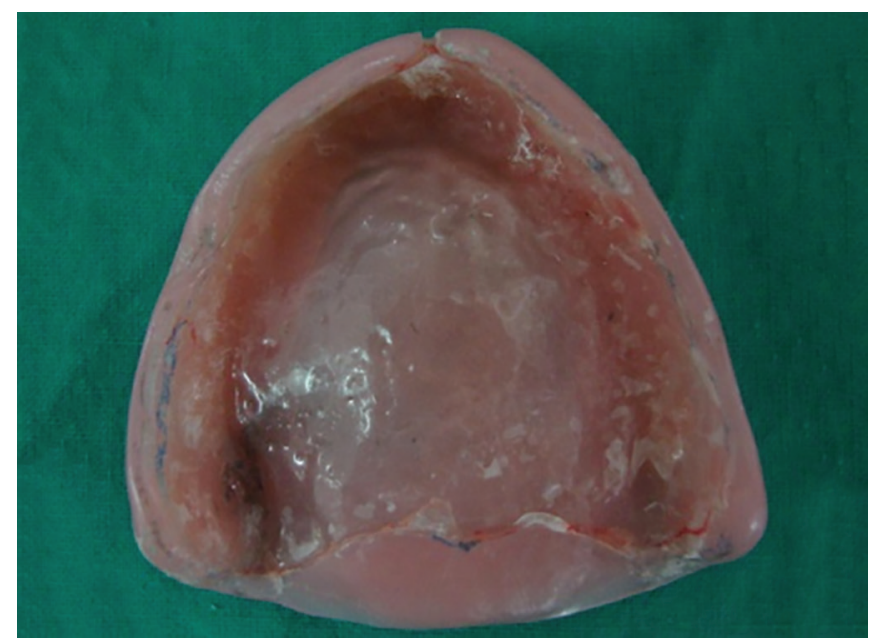

Fig. 14: Liquid-supported denture with shock-absorbing effect

The seal was checked properly. In areas of leakage, it was resealed till a perfect seal was obtained at the junction. A viscous liquid, i.e., glycerin, was filled through the holes (Fig. 13) and the vertical dimension was checked simultaneously. The holes were then sealed with self-cure acrylic resin.

Denture insertion was done and again it was evaluated for stability, esthetics, and occlusion (Fig. 14). Denture care instructions were given to the patient. Patient was told to clean the tissue surface using soft cloth. Recall appointments were scheduled at 1 day, 1 week, 1 month, and 3 months. At 1 week's appointment, patient complained of floating feeling (i.e., patient had a feeling that the denture was not very closely adapted to the underlying foundation area). But at 3 months recall appointment, the patient was comfortably using the denture. The denture was well maintained. Thereafter, the patient was recalled every 3 months for checking any rupture of polyethylene sheet and seal (Fig. 15). In case of liquid leak, the denture was refilled.

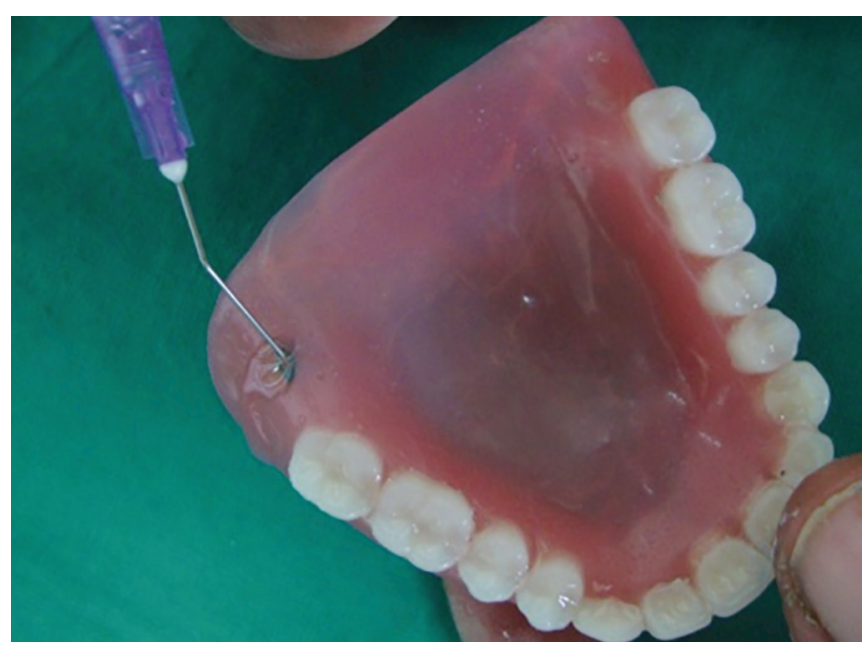

Fig. 13: Incorporation of glycerin as a liquid medium

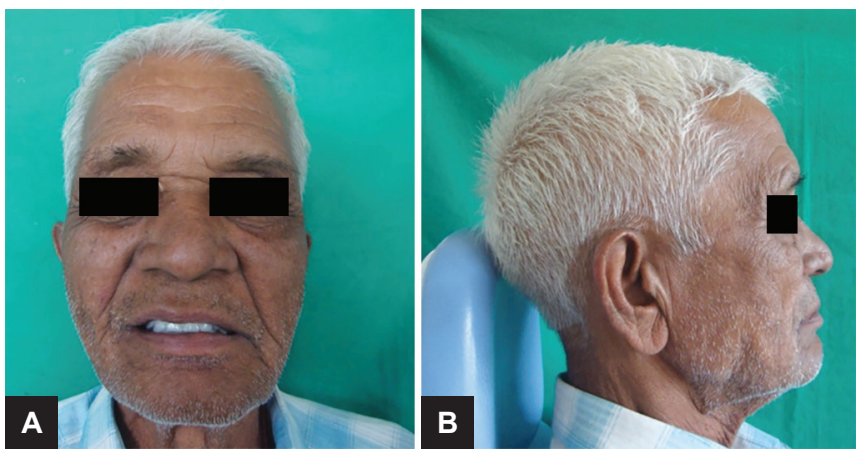

Fig. 15: Postoperative view

\section{DISCUSSION}

The prosthodontic management of patients with facial palsy should satisfy the esthetic and functional needs of the patient. Facial palsy is indicative of neurological involvement. Patients with this disease can be treated, but it is essential to understand their problems. Denture retention, maxillomandibular relation records, and supporting muscles are added denture problems in these patients. ${ }^{5}$ A balance between esthetic and functional needs of the patient has to be achieved. Thus, a labial commissural sag is provided to facilitate drinking and speaking. This, however, definitely compromises the esthetics, as extra cheek support cannot be provided in such patients. ${ }^{7}$

This patient was rehabilitated with liquid-supported maxillary complete denture and mandibular complete denture with neutral zone technique. The principle of this design was that a liquid-supported denture is flexible and continuously adapts itself to the mucosa. ${ }^{8}$ However, it is also rigid enough to support the teeth during actual use. Thus, the denture base is covered with a close-fitting flexible foil to keep a thin film of liquid in its place. This design will act as a continuous reliner for the denture and thus has an advantage over the existing denture designs. When no forces are applied, the foil remains in 
the resting position, acting as a soft liner; and when the dentures are in use, vertically directed loads are distributed in all directions by the liquid resulting in optimal stress distribution. This helps in long-term preservation of bone and soft tissues. ${ }^{8,9}$

In this case, polyethylene thermoplastic clear sheet (Easy-Vac Gasket) was used because of its softness, flexibility, and biocompatibility. For a liquid cushion, glycerin was used, which is clear, viscous, and biocompatible and also has been used as a vehicle in liquid medications. ${ }^{10}$

The aim of the neutral zone is to construct a denture in muscle balance, i.e., a denture which is in harmony with the surroundings to provide optimum stability, retention, and comfort. The neutral zone philosophy is based on the concept that for each individual patient there exists within the denture space a specific area where the function of the musculature will not unseat the denture, and at the same time where the forces generated by the tongue are neutralized by the forces generated by the lips and cheeks. ${ }^{11}$ Hence, in unilateral facial paralysis patient, it is essential to record neutral zone because of imbalanced forces generated by unaffected and affected side causing instability in dentures.

\section{CONCLUSION}

Planning complete denture in compromised patients is a challenging task and requires modification of traditional procedures. A complete denture will not have a good prognosis if it violates the foundation on which it rests. Liquid-supported dentures eliminate the main disadvantages encountered due to rigid denture base materials, thereby providing proper retention, stability, support, and comfort to the patient. This technique in combination with neutral zone allows continued adaptation of the denture to the mucosa in the resting and functional states.

This case report presents a modified procedure for rehabilitation of compromised patients enabling to take a step forward for the care of these patients to lead a normal life.

\section{REFERENCES}

1. Spillane J, Prasad K, Yadav R. Bickerstaffs neurological examination in clinical practice. 7th ed. India: Wiley; 2013.

2. House JW, Brackmann DE. Facial nerve grading system. Otolarngol Head Neck Surg 1985 Apr;93(2):146-147.

3. Beresin VE, Schiesser FJ. The neutral zone in complete dentures. J Prosthet Dent 2006 Feb;95(2):93-100.

4. Alfano SG, Leupold RJ. Using the neutral zone to obtain maxillomandibular relationship records for complete denture patients. J Prosthet Dent 2001 Jun;85(6):621-623.

5. Rahn AO, Heartwell CM Jr. Textbook of complete dentures. 5th ed. Hamilton (ON): BC Decker; 2002. p. 134.

6. Padmaja S. Liquid-supported denture and neutral zone for atrophic residual ridges: a case report. Peoples J Sci Res 2012 Jan;5(1):52-55.

7. Larsen SJ, Carter JF, Abrahamian HA. Prosthetic support for unilateral facial paralysis. J Prosthet Dent 1976 Feb;35(2): 192-201.

8. Davidson CL, Boere G. Liquid-supported dentures. Part I: theoretical and technical considerations. J Prosthet Dent 1990 Mar;63(3):303-306

9. Boere G, Koomen H, Davidson CL. Liquid-supported dentures. Part II: clinical study, a preliminary report. J Prosthet Dent 1990 Apr;63(4):434-436.

10. Omprakash YV, Hallikerimath RB, Gangadhar SA. Liquidsupported dentures: a soft option-a case report. J Indian Prosthodontic Soc 2004;4(1):31-34.

11. Kursoglu P, Ari N, Calikkocaoglu S. Using tissue conditioner material in neutral zone technique. N Y State Dent J 2007 Jan;73(1):40-42. 